Revista Iberoamericana. Vol. LXVI, Núm. 190, Enero-Marzo 2000, 163-174

\title{
EL HILO DE ARACHNÉ Y LA TOMA DE DISTANCIA ${ }^{1}$
}

POR

José Amícola

Universidad Nacional de La Plata

1. El hilo QUe GUía

\author{
Minos: Las madres no cuentan. \\ Todo está en el caliente germen que las elige y las usa. \\ Cortázar, Los reyes
}

Volveré hoy a sostener la idea de una línea genealógica entre Roberto Arlt (19001932), Julio Cortázar (1914-1984) y Manuel Puig (1932-1990), considerándola nuevamente no como una cadena de influencias literarias y de fuentes, sino de la ocupación de un lugar no hollado antes. ${ }^{2}$ Se trata, entonces, de una interrelación de fuerzas dentro de un campo y la construcción que esto permite a los receptores a partir de la imagen que los agentes dan de sí mismos dentro de esa área (Dalmaroni). Este campo de fuerzas en tensión implica en primera instancia una poética que aunque sea implícita tiene un valor que debe entenderse en sentido contrastivo, es decir como punta de lanza contra otra u otras poéticas, como se muestra claramente en el caso de Arlt (Viñas, Jitrik, Sarlo y Borré). En mi tesis, la línea ArltCortázar-Puig tiene una continuidad, en primera instancia con respecto a un astro de primera magnitud (Borges) en relación al cual estos autores se colocan en una actitud forzosa de magnitudes menores, según los signos de consenso que reciben de los diferentes públicos envueltos en el proceso receptivo. Es cierto, además, que mi tesis ha encontrado especiales reservas en el caso de la figura de Cortázar, quien parece avenirse mal a integrar la tríada. ${ }^{3}$ Esto sucedería - y soy consciente de ello- a causa de la postura de Cortázar, menos distanciada del imán que representaba el universo borgeano. En mi diagrama en forma de un ROMBO, entonces, vengo ubicando a la tercera figura del ABC, en la posición cercana

\footnotetext{
${ }^{1}$ El presente trabajo ha sido leído en el XXXII Congreso del IILI, Santiago de Chile, junio-julio de 1998.

2 La tesis acerca de una línea geneológica no entendida como líneas de influencias, sino como ampliación del lector aparece en mis trabajos de 1992; véase Amícola (Manuel Puig y la tela que atrapa), Cap. 1; 15-44.

3 Para la polémica en torno a esta genealogía, pueden verse especialmente los debates en torno del tema en Amícola/Speranza, Encuentro "Manuel Puig” y Giordano.
} 
a Borges en el vértice derecho, mientras que Puig aparecería en el otro extremo de la figura, en la punta opuesta al gran Maestro. ${ }^{4}$

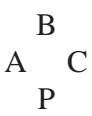

Esta organización me permitiría, por otra parte, afirmar mi convicción del lugar que le corresponde a Puig en las letras argentinas. La intención de la presente comunicación es, por lo tanto, hacer hincapié no sólo en la tesis arriba esbozada, sino reforzar mi posición en el punto aparentemente más flojo de la argumentación, es decir: dar especial realce al caso Cortázar como integrante de la genealogía. En este sentido, me propongo unir mi interés por los conceptos de género en el sentido de "gender" y "genre" en el tratamiento de tres obras teatrales de los tres autores ACP, que han sido conocidos, paradójicamente, en primera instancia, como narradores. Ello llevará consigo el intento simultáneo de hablar de una poética (la teatral, por un lado, y la narrativa, por otro), así como de principios "leitmotívicos”(la imposición social de los roles sexuales). Echar mano a obras tan laterales como “Saverio el cruel” (1936), de Arlt, Los reyes (1947), de Cortázar y “El misterio del ramo de rosas" (1987), de Puig sería, por lo tanto, una estratagema no sólo para entrar por la puerta menor, sino que esta astucia de la razón hermenéutica permitiría detectar elementos que podrían dar claves a nivel contrastivo para las respectivas actividades de los tres novelistas. Jugando a contrapelo con lo que los textos parecen decirnos, intentaré extraer claves precisamente de un texto de Cortázar aparentemente desgajado del contexto en que pretendo colocarlo, dado que puede considerárselo efectivamente a la sombra del Padre por su condición de libresco y por sus motivos, así como por la inserción de la primera edición del texto en una revista dirigida por Borges. ${ }^{5}$ Sin embargo, será mi intención destacar, al mismo tiempo, que estas obras teatrales, menores en la producción total de sus autores, serán aquí leídas en función de las paradigmáticas obras narrativas Los siete locos/Los lanzallamas

\footnotetext{
${ }^{4}$ La ironía o distancia irónica en ABC y especialmente en BB (reduplicación por el efecto del Doble con Bioy Casares) es el quid que falta en Puig y que hace no sólo la ruptura con el gran Maestro (repuesto por Piglia en el campo literario argentino después de la deflación de su figura provocada entre las izquierdas), sino lo propio de Puig. Piglia — como gran recolocador de figuras en el campo literario argentino - había roto la dicotomía ARLT-BORGES, para elevar a Borges contra las lecturas políticas de los 60 y 70, y contra Contorno. Ahora Piglia estaría declarando en entrevistas que no hay oposición entre Borges y Puig. En rigor, esto es un operativo para elevar a Puig, según se desprendería de lo anterior. No es que Piglia quiera decir que Borges y Puig hacen lo mismo, o "hacer lo mismo" significa aquí algo diferente, a mi juicio. Que ambos hagan lo mismo, es decir: poner notas al pie, quebrar el principio de lo que es importante y lo que no lo es, la lectura del cine, etc., significa que ambos están en el mismo campo. Pertenecen ambos a la literatura argentina, donde esos elementos ya son moneda de cambio. Ambos están lejos tanto de un costumbrismo como de un realismo mágico. Ambos están inmersos en una cultura metropolitana, urbana, que fue inaugurada por Arlt, en una capital que era un Centro, aunque en la periferia. Ese fue el humus de ABCP.

5 La revista era Anales de Buenos Aires 20-22. Agradezco esta información a mi colega Ana M.González de Tobia de la UNLP, así como la discusión de algunos aspectos de los mitos griegos.
} 
(1929-1931), Rayuela (1963) y El beso de la mujer araña (1976), que han sido consideradas por sus productores, así como por los públicos más disímiles, como culminaciones y, por lo tanto, como imágenes modélicas, no sólo de concreción de la voz propia de cada escritor, sino especialmente como colocación de una piedra miliar en un camino enfrentado a la monumentalidad babélica del Padre (ver Colás, Cosgrove). Es Cortázar, evidentemente, el que vacila en su toma de distancia de la figura faro, especialmente en sus primeros momentos durante la década del 40. Sin embargo, la elección del género ("poema dramático”) para su texto indica — en mi lectura— que a pesar de hallarse bajo la égida borgeana intenta tomar distancia, recurriendo a otros precursores y a otros géneros no borgeanos que lo llevan a Eurípides y a Lorca, ${ }^{6}$ teñidos de surrealismo, donde no está exenta una revisitación subjetiva de los mitos clásicos, como habían aparecido en John Keats (Cabrero 83).

En cuanto a la apertura hacia la elaboración genealógica que postula el presente trabajo, es necesario volver a subrayar aquí que ella no pone el acento en la vieja concepción de un intercambio de influencias entre los escritores. En este sentido, la exclusiva consideración de lo que ha sucedido en la literatura Argentina del siglo XX con absoluta prescindencia de lo que ocurría en el orden internacional (con la lectura de autores como Faulkner, Durrell o Gombrowicz, que marcaron a las generaciones argentinas a partir de los años 60), trata de probar que un campo literario está lejos de ser un lugar idílico de mutuas fidelidades y que, más bien, representa un "campo minado", donde cada figura intenta trazar un sendero que lo proyecta hacia el futuro eligiendo en primera instancia los antepasados con los que quisiera integrar un futuro panteón heroico NACIONAL. En la literatura argentina no ha habido un caso más flagrante de esta autocolocación en una tradición interna que la tarea lenta y coherente del propio Borges para ubicarse en la línea sucesoria de Leopoldo Lugones, desde sus primeros escritos hasta un libro como El hacedor (1960), dedicado a su antecesor. Una lectura de esta batalla borgeana indicaría, entonces, que si la primera mitad del siglo XX en la Argentina estuvo bajo la idea consensuada de que el cetro literario estaba en manos de Leopoldo Lugones, la segunda mitad del siglo habría de pertenecerle a Borges. Si esta segunda figura sustituye a la primera en la arena argentina, esto no sucede tanto o tan sólo por el reconocimiento internacional que Borges obtiene a partir de Caillois, Foucault, Bloom, Derrida, Steiner, etc., sino especialmente por la lucha interna preparada en los escritos de Borges, quien, determinando cómo debía escribir un autor argentino, indicaba que Lugones había muerto (no en 1939 — como en realidad había ocurrido—, sino en 1960) y que no había nadie mejor que él mismo para suplantarlo. La postulación de las páginas que siguen se resume, entonces, en la idea de que esta lucha continúa a fines del milenio. Si el siglo XX estuvo distribuido en la Argentina entre los viejos Maestros Lugones y Borges, la incógnita pasa ahora por tratar de dilucidar cuáles son los autores que realmente matan al Padre, condición indispensable para la evolución literaria. La lectura del prólogo de Arlt a su novela Los lanzallamas —aparecida en 1931—, revela en primera instancia el resentimiento hacia quienes leen a Joyce en inglés (como una estocada a Borges), y la propia intención de Arlt de posicionamiento como contrafigura de Borges. La muerte prematura de Arlt (en 1942) restó fuerza a su escaramuza. Sin embargo, va a ser Cortázar, en su

\footnotetext{
${ }^{6}$ Para las cadencias imitadas de García Lorca véase este pasaje: "Minotauro: Ya no mía, ya viento y abeja o el potro del alba - Granada, ríos, azulado tomillo, Ariana [...]” (Cortázar, Los reyes 73).
} 
reiterada autofiliación con Arlt, quien va a retomar la pelea (dentro de esta propuesta de lectura) tratando de relativizar su compleja relación de amor-odio hacia Borges, a quien, en verdad, no podía dejar de reconocer como su Maestro. Cortázar, en su indecisión, se queda así a medio camino entre su conflicto por encontrar su voz propia y su admiración por Borges, un tema crucial en la literatura argentina (Amícola, "La noche”). En la tríada sucesoria, sólo Puig ha venido a contestar de modo más absoluto a las preguntas que habían quedado pendientes, que aquí versarán especialmente sobre la relación gender-genre.

2. El HILO QUE MIDE O ATA

Minos: Una mujer no sabe mirar. Sólo ve sus sueños.

Cortázar, Los reyes

En el caso de Puig, sus piezas de teatro parecerían responder a un camino natural genérico, dado que sus novelas explotaban masivamente el diálogo, aunque eran obras que podían pasar al teatro, siempre y cuando mediara una adaptación. Ello me había permitido suponer que no había tanta diferencia entre las novelas y sus obras teatrales (por lo menos, las hasta ahora éditas). ${ }^{7}$ El diálogo en sus novelas constituía, en rigor, una pista hacia la oralidad, la renuncia al narrador autoritario y la presentificación del suceso en la actualidad del lector. Por otra parte, las novelas de Puig (como las de Arlt) mezclaban, asimismo, los pasajes de sueños alucinatorios con recursos propios de una literatura mimética. Sin embargo, Puig y los otros dos autores que lo preceden en esta genealogía que sostengo son conscientes de que al escribir una obra de teatro en la Argentina, cada escritor debe liberarse primero de una dramaturgia costumbrista signada por el "sainete criollo" y el grotesco de filiación pirandelliana. Hay, pues, en las piezas que analizaré una comunidad de tensiones entre polos de la así llamada realidad, que alerta sobre el callejón sin salida de la representación mimética del cine, según observa Puig en el prólogo a "La cara del villano"8 (lo que valdría también para su concepción del teatro).

Ahora bien, Puig comienza a escribir teatro como apartamiento de la escritura novelística que conllevaba cierta imposición mimética y una dimensión analítica según la comprensión del género novela que él realizaba. Se daba, por otro lado, el sentimiento de encono frente a la crítica periodística que había recibido mal sus novelas de 1979, 1981 y 1982. Así, en 1983 publica no sólo la adaptación teatral de El beso de la mujer araña, en la que venía trabajando desde 1981, sino también la surrealista obra "Bajo un manto de estrellas”, que podría entenderse como un deseo de tomar distancia del género novela, que habría sofocado, al mismo tiempo, la veta escénica de sus primeros guiones, aunque le había

\footnotetext{
${ }^{7}$ Puig me había contestado en 1981 acerca de esta diferencia genérica entre la novela dialogada y el drama que seguramente él terminaría recalando en el teatro.

${ }^{8}$ El pasaje al que me refiero se halla en Puig (La cara, 11) y dice así: "Mis novelas [...] pretenden siempre una reconstrucción directa de la realidad; de ahí su para mí imperativa naturaleza analítica. La síntesis, en cambio, va bien con la alegoría, con el sueño. ¿Qué mejor ejemplo de síntesis que nuestros sueños de cada noche? El cine requiere síntesis y, por lo tanto, es el vehículo ideal de la alegoría, del sueño”.
} 
traído tanto prestigio internacional. ${ }^{9}$ La distancia de la novelística es un intento paralelo en Arlt, Cortázar y Puig a otra toma de distancia que había surgido en el momento de salir a la palestra de la escritura, la de una separación de la figura señera de la literatura argentina que cada uno de los autores analizados logró dejando tras sí huellas más o menos visibles. ${ }^{10}$

\section{Arachné}

Teseo [a Minos]: Este azar, igual que todos, se ha venido tejiendo con minucia y el Minotauro lo expone

a la luz como envuelve el rocío en su delación plateada el tapiz de Aracné.

Nadie nos oye y yo soy Teseo. Es decir, soy también Minos.

Cortázar, Los reyes

Veamos ahora el caso Cortázar. Este autor no deja de sentir — según una asociación de vieja data también documentada en Shakespeare- la cercanía de los mitos de Ariadne con el de Arachné, aunque ello no incida en la confusión de los personajes. ${ }^{11}$ La cercanía, con todo, es significativa, en tanto muestra la connotación de la astucia como elemento característicamente femenino, unido a la de engaño visual que conduce a una trampa y a la muerte, aunque ella esté presentada en un plano estilizadamente estético por la mención de una red plateada. El hilo de Ariadne/Ariadna para encontrar la salida del laberinto es, además, un atributo que alude a una estratagema, pero, al mismo tiempo, a la rueca y a los trabajos femeniles del pasado, por donde parecía natural una vinculación con el tejido de la araña (Hunter). La astucia de la “Ariana” de Cortázar radica en que espera que quien tome el cabo del hilo sea su amado hermano Minotauro, símbolo oculto del Poeta como figura diferente y, por lo tanto, monstruosa (Harss 263-264).

Es mi intención, por otra parte, señalar la vinculación de este motivo de Cortázar en la matriz novelística de Rayuela titulada por el propio autor “La araña”. Allí, según lo señala Ana María Barrenechea (Cortázar/Barrenechea Cuaderno), el hombre aprisiona a la mujeraraña mientras duerme enredándola en una trama de hilos que la fijan en sus atributos y la inmovilizan como devoradora, ahora devorada (sexualmente) por la supuesta víctima, en un transvasamiento que iguala la ingestión con la cópula. El hombre convierte con su mirada a la mujer en araña, pero para aprisionarla y poseerla: la víctima potencial (desde la mirada obsesionada del macho) se venga y devora sexualmente a su victimario, en un juego

\footnotetext{
${ }^{9}$ El estudio de los manuscritos nos revela, por otro lado, que este amor por la escena no había muerto, dado que no cesó nunca de pensar en ella y, finalmente, escribió un guión cinematográfico (no filmado todavía) en inglés — su primera lengua literaria— con el nombre de "Vivaldi".

${ }^{10}$ En un sentido, la obra de teatro de Puig no difiere de las novelas: parecerían éstas más bien un estadio previo hacia la condensación teatral y hacia la desaparición del narrador. En ambos géneros, en Puig se cuenta mientras se dialoga.

${ }^{11}$ El mito de Arachné ha sido difundido y popularizado por Ovidio en sus Metamorfosis (libro 6, 1145).
} 
explícito donde se despliegan la sexualidad y el poder. Pero, si el miedo del hombre a ser devorado por la hembra está presente en esta matriz novelística de Cortázar, no es menos cierto que el motivo de los hilos se repite en el mismo quasi final del protagonista Oliveira atrapado y atrapando a su doble, Traveler, en una trama falocéntrica. En este sentido los textos de Cortázar, mayores y menores, sirven para afirmar que lo que está en juego al mismo tiempo que el lugar común de la astucia femenina es la contracara del dominio falocrático. Así puede contextualizarse ahora el duelo verbal entre Susana y Saverio de Arlt:

Saverio: Si hace quince días alguien me hubiera dicho que existía una mujer capaz de urdir semejante trama, me hubiera conceptuado feliz de conocerla. Hoy su capacidad de fingimiento se vuelve contra usted. ¿Quién puede sentirse confiadamente a su lado? Hay un fondo repugnante en usted. (Arlt 483)

Susana (poniéndose de pie a su lado) — Soy la novia espléndida que tu corazón esperaba. Mírame, amado. Me gustaría envolverte entre mis anillos, como si fuera una serpiente de los trópicos (Arlt 484). ${ }^{12}$

4. GENDER Y GÉNERO LITERARIO

Minos: Los hombres sostendrán a las vírgenes y olvidarán su miedo en el consuelo viril.

Cortázar, Los reyes

Si consideramos que Arlt y Cortázar están empleando un tono trágico que alude al drama clásico en sus cadencias sonoras y en sus motivos, podremos sostener también la idea de que esta alusión remite necesariamente a Eurípides, en tanto en ningún otro de los dramaturgos griegos se presenta el problema de la mujer y de la fuerza de una lucha entre matriarcado y patriarcado como en este representante díscolo de la tragedia (Rostagni). ${ }^{13}$ Es también con Eurípides cuando aparece una hondura que percibimos como llamativamente moderna (Cabrero 97). En este sentido, las tres pequeñas piezas teatrales analizadas aquí presentan reminiscencias de esta presencia de lo femenino como fuerza de poder. ${ }^{14}$ En otro sentido, Puig es el que va más lejos, no sólo porque prefiere la lengua conversacional y abandona el tono trágico, sino porque como en su novela El beso de la mujer araña retoma aquí en la Paciente y la Enfermera el tema de gender, al colocar enfrentados dos interlocutores del mismo sexo y tematizar de ese modo los estereotipos sexuales, pero también los enfrentamientos del Poder falocrático, algo que a los heterosexuales Arlt y Cortázar se les había escapado.

12 Para una lectura feminista de las “mujeres que matan” en la literatura argentina, véase Ludmer ("Mujeres que matan”).

${ }^{13}$ Eurípides fue, además, el dramaturgo de la ruptura con la tradición que no siempre dio fin trágico a sus obras y que, por otro lado, permitió mayor espacio a la voz de la mujer con un lenguaje cotidiano. Al mismo tiempo, dio también relieve a un reconocimiento personal y a una maduración (Rostagni 187).

${ }^{14}$ Véase el texto de Puig: "Paciente: Falsas ¡las dos! Todas las mujeres son falsas, todas son una porquería, por eso doy gracias a Dios de tener un nieto varón...Es lo único que quiero en el mundo...” (Puig, "El misterio" 139). 
Los reyes, entretanto, nos ayuda a comprender, en mi refuncionalización de ese texto, que tanto Arlt como Puig luchaban contra una concepción del realismo. Por otro lado, Arlt y Puig querían tomar distancia de las novelas que los habían llevado a la fama y con las que corrían el riesgo de incurrir en una repetición. Por ello, vemos que Susana en la obra de Arlt asume la voz impostada del teatro clásico (que a su autor le resulta más escribible que el tono de un Juan Moreira del sainete criollo), con estas palabras:

Susana: ¿Lo escucharon? (Suplicante) ¿Levantaron acta de su frialdad burlona? Los hijos son un consuelo. ¡Contéstanos, hombre siniestro! ¿Fuiste consuelo de la que te engendró? ¿Qué madre venenosa adobó en la cuna tus malos instintos? ¿Callas? ¿Qué nodriza te amamantó con leche de perversidad? (Arlt 480).

Arlt está asumiendo un tono genérico elevado para combinarlo con el reciente lenguaje surrealista que comienza a llegar a Buenos Aires en la década del 30, mientras que Cortázar dirigirá su mirada, once años más tarde, a las cadencias de Keats o de García Lorca. Puig, finalmente, se inspirará en el cine de Hollywood (igualmente marcado por huellas de una presencia estilística europea a causa del origen de los equipos cinematográficos). Es en el lenguaje de este cine donde la presencia de espejos era el paso posible para marcar un desdoblamiento de lapersonalidad. ${ }^{15}$ Cierto hálito del surrealismo como común denominador de estas obras dejan la impronta, entonces, de una factura similar por medio de tres aspiraciones que según Peter Bürger caracterizarían a esta corriente: la unión de los opuestos, la liberación del deseo y la infracción a las reglas vigentes (86). En las tres obras se abren las compuertas interiores de los individuos, demonizando, al mismo tiempo, una tecnocracia que se considerará excesiva y perjudicial a la civilización, aunque los motivos que se esgriman sean diferentes.

5. TRES ESFERAS DISCURSIVAS: LA IDEOLOGÍA, EL MITO Y EL INCONSCIENTE

Minotauro [a Teseo] Parece que miraras a través de mí. No me ves con tus ojos, no es con los ojos que se enfrenta a los mitos.

Cortázar, Los reyes

En "El misterio del ramo de rosas" estamos nuevamente ante un espacio clausurado en mayor o menor medida - por los muros de una habitación de clínica con una paciente postrada en la cama; ese espacio no es menos un "a puertas cerradas" que el laberinto de Los reyes cortazariano. Ahora bien, Puig surge literariamente en el momento de cisma entre la influencia de Sartre y la aparición en el cielo argentino del astro de Lacan, según se documenta en el caso de la figura marcadora de caminos como lo es Oscar Masotta (Correas). ${ }^{16}$ La obra de Puig aparece efectivamente en el momento en que la teoría se

\footnotetext{
${ }^{15}$ Véase, por ejemplo, el film "Kitty Foyle”, de 1935 dirigido por Sam Wood.

${ }^{16}$ Véase al respecto sus colaboraciones en la Revista Centro que tratan de Arlt, Sartre y Lacan (Masotta, "Roberto Arlt” y "La fenomenología”).
} 
resquebraja. De allí que aun los críticos adversos deberán reconocer en Puig su intención de ruptura. Esta ruptura era de igual importancia a la que estaba aconteciendo en otras esferas, de las que el famoso Instituto Di Tella no dejaba de hacerse eco durante los años 60 . Por otra parte, la lectura que propongo hace hincapié en tres aspectos de tres obras laterales que pueden verse como un continuum, pero también laterales a una línea hegemónica anti-romántica. Me refiero a la marca que Arlt imprime a la suya en LA FUERZA DE LA IDEOLOGIA, mientras Cortázar se propone subrayar LA FUERZA DEL MITO, y Puig, por su parte, LA FUERZA DEL INCONSCIENTE. ${ }^{17}$ Estos tres episodios sociales aparecen representados en las tres piezas comentadas a través del tópico de la fabulación.

Arlt estuvo empeñado en su obra por enmarcar lo literario dentro de la inmediatez política (Amícola). Ello no es sólo evidente en sus novelas, sino también en sus obras teatrales, aunque en el género dramático la impronta surrealista parezca esfumar las preocupaciones de denuncia ideológica. Cortázar, por su parte, engarzó su producción no sólo en las ideas del "compromiso”, según la fórmula de Sartre, llevando un paso más adelante lo iniciado por Arlt, sino que hizo hincapié en la fuerza de la imaginación contra toda lectura demasiado literal de un "realismo socialista” (huracán que soplaba desde La Habana). Prueba de ello son no sólo sus declaraciones más politizadas de su última época, donde a pesar de todo su compromiso ideológico sigue reservándose el derecho como creador de elegir temas y modos de su creación, sino también sus obras más tempranas. La pasión por las culturas primitivas (heredada del universalismo de Borges) lo lleva a poner su atención no en el helenismo tardío, sino, por ejemplo, en la civilización cicládica, como fenómeno que Cortázar lee a nivel muy hondo de fundación mítica, pero conectada con el inconsciente individual o colectivo (según sucede en cuentos como "El ídolo de las Cícladas” o "Las ménades”, del libro Final del juego, de 1964). Si Puig no deja de lado la deconstrucción ideológica iniciada en Arlt, también puede decirse que "supera” —en sentido hegeliano de una Aufhebung como negación y absorción de las fases anteriorestanto ese universo arltiano, como el territorio ganado por Cortázar para la literatura argentina: la interrelación del mito y el buceo psicológico en una nueva síntesis, que aquí denomino LA FUERZA DEL INCONSCIENTE. ${ }^{18}$

\footnotetext{
${ }^{17}$ Estas tres magnitudes sociales o psicosociales se vinculan a través de los vasos comunicantes de la lengua, y, por ello, no es de extrañar que una disciplina joven como lo es el análisis del discurso las haya puesto en relación.

18 El único de los cuatro autores que ha merecido un catálogo bibliográfico exhaustivo sobre su recepción, es hasta el momento Manuel Puig (véase Martí-Peña).
} 
6. El MisTERIO DE LA FÁBULA

Minotauro [a Teseo]:

Ni siquiera tu espada me está justamente destinada. Deberías golpear con una fórmula, un ensalmo: con otra fábula.

Cortázar, Los reyes

Las dos protagonistas de la obra de Puig arman en la pieza teatral comentada una fábula dialógica, una fábula que sella la paz y la amistad, pero también marca la aceptación de sí mismas en una cadena sucesoria como mujeres. El final apunta, entonces, a una alternativa irresuelta en la vida de una mujer pero claramente asumida entre la realización personal o la elección por la esfera afectiva - aunque como esfera excluyente una de la otra. En cuanto a los títulos, Cortázar seguirá prefiriendo la mesura borgeana, mientras sus dos colegas se entregan a la bivocalidad de lo ambiguo: quién es “el cruel”, en el caso del texto de Arlt, y quién, en el otro caso, si no los propios personajes de Puig son los que necesitan crearse un misterio que, en rigor, no es más que una cita del género de enigma. ${ }^{19} \mathrm{Y}$, en este sentido, no va más allá de lo que proponía Pubis angelical y que las feministas mexicanas veían como un tributo al tradicionalismo machista. ${ }^{20}$ Con todo, leída a la luz de las obras de Arlt y Cortázar, "El misterio del ramo de rosas" representa una torsión porque escenifica el conflicto del ser mujer en un universo cerrado en que se pone el falocratismo entre paréntesis, como se colocaban entre paréntesis muchos de los prejuicios del hombre unidimensional de los 70 en el final de El beso de la mujer araña..$^{21}$ Como en la novela, la cuestión es dónde se instala el estereotipo de la astucia cuando la contienda no implica en

\footnotetext{
${ }^{19}$ La tradición de la escritura liberadora escrita por mujeres durante el siglo XIX proponía un volver la mirada a una línea sucesoria femenina, donde abuela-madre-nieta formaran una amalgama de aceptación de esa condición (como sucede en Pubis angelical). El texto de Puig parece aludir a esa línea, pero la corrige sacándola de la historia familiar para extenderla a cualquier otra mujer. Esta es mi interpretación, entonces, de la relación anudada finalmente entre la Paciente y la Enfermera en la pieza que comento.

${ }^{20}$ Para conocer la reacción de las feministas mexicanas según Puig, véanse sus declaraciones en Amícola, Manuel Puig, Apéndice. La astucia femenina se nota en la Susana de Arlt, en la Ariana de Cortázar y en la Paciente de Puig. Se trata, en rigor, de la astucia del débil o también de la fuerza del aparentemente débil y la debilidad del aparentemente fuerte. Al poner frente a frente a dos mujeres, el juego de la astucia en la propuesta de Puig va más lejos del horizonte de expectativas tradicional, puesto que no se sabe cuál vencerá. Esta es una de las torsiones que la obra de Puig causa al modelo maniqueo del enfrentamiento de los sexos y una indagación que, en el fondo, tiene que ver con los estereotipos de gender.

${ }^{21}$ La comida sustituye en "El misterio del ramo de rosas" al deseo erótico, tal como este aparece en su cuarta novela. En cuanto a los aportes de la crítica geneticista, habría que decir que es justamente en el tema de la fabulación del misterio donde Puig ha escrito a mano las mayores correcciones. Ello señalaría la importancia que le estaba dando a este nivel dentro de la economía de la obra. Ello se vincula, además, con el uso de lo dialógico en el sentido bajtiniano, puesto que el diálogo final de las dos mujeres es una construcción conjunta en la que cada una abreva de las palabras de su interlocutora para combinar la fábula.
} 
los dos interlocutores a un sexo habitualmente considerado más débil que el otro. Lo que queda es la fuerza de la Fábula como la instancia más poderosa, es decir también una apología del Arte. Por ello, en mi recontextualización, las últimas líneas de esta obra marcan un puente con Los reyes, donde se decía:

Tendremos que mentir, continuamente mentir hasta pagar este rescate. Sólo en secreto, a la hora en que las almas eligen a solas su rumbo [...] ; Qué extrañas palabras dijiste, señor de los juegos! / Vienen ya. ¿Por qué recomienzas la danza, Nydia? ¿Por qué te da mi cítara la medida sonora? (Cortázar, Los reyes 74).

Y en "El misterio del ramo de rosas":

Enfermera: De pronto él se acuerda de que tiene que volver al lugar de donde vino. El deber lo obliga. Una promesa sagrada. Se tiene que ir. Ya se fue. Paciente: Y usted se desespera. Pero esa es la gran noche de su vida. La noche en que decide su destino. (Con humor) $\mathrm{O}$ la ciencia, o el amor. O la actividad frenética de los hospitales, o la espera en el jardín, (languideciendo) atardecer tras atardecer, mareada de perfume de jazmín (Puig 158).

Cortázar y Puig cantan, efectivamente, al poder de la poesía y del poeta a partir de un tono de fabulación que es el que queda resonando al final del texto: el misterio de la anonimia de un ramo o la monstruosidad de lo que ha sido recluido para que no sea mostrado. Ariana y Minotauro o la Paciente y la Enfermera se confabulan para dar a luz la fábula, una fábula que sale de los personajes como narradores vicarios donde se juega también el principio relativizado del gender.

Volviendo al comienzo de este trabajo, podría decirse que los tres sucesores de Borges se esmeran en corregir la propuesta del Padre al declarar programáticamente la necesidad de inserción de lo literario en el ORDEN DE LO POLÍTICO, al mismo tiempo que se afanan por mostrar la interpenetración de ese orden con LO SEXUAL. Del mismo modo, la persistencia del Maestro para evitar todo contacto con las áreas más revolucionarias del pensamiento del siglo XX, como el marxismo y el psicoanálisis, ponen de manifiesto en qué medida son los hijos quienes van proclamar la condición de insoslayables de esos dos ámbitos. Como es sabido, estos dos dominios han sido particularmente aislados asépticamente como tabúes innombrables en la obra de Borges. Para concentrarnos especialmente en la segunda de las dos categorías, habría que decir que el pudor decimonónico de Borges frente a lo sexual (para no hablar siquiera de gender) se manifiesta en el modo sutil en que se expresa sin nombrar en un cuento en tanto que "La secta del Fénix”, o aparece bajo el cálculo frío como elemento objetivizado como pieza narratológica en la frontera entre relato detectivesco y juego de ajedrez (en “Emma Zunz”). La línea Arlt-Cortázar-Puig no sólo va a tratar toda la gama de la actividad sexual, desde el onanismo, la homosexualidad, el "amor libre sesentista”, el adulterio y las perversiones, sino que va a ir acercándose paulatinamente a un debate en cuanto a la parte de hábitos sexuales que la sociedad impone a sus miembros basándose en pretendidas esencias biológicas (es decir, el tema del “gender”). En este sentido, cada uno de los sucesores aparece rodeado del clima propio de su década. En la obra de Arlt, sus prejuicios frente a lo femenino son típicos de la década del 30 (tanto en la Argentina como en el extranjero) — algo que viene a probar el estudio de Masotta sobre el 
autor a partir de la idea de "traición”- ("Roberto Arlt” y Sexo y traición). Cortázar, por su parte, imbuido del espíritu de los 60 , consiente en acordarle a la mujer la sexualidad que la década le concede, pero no puede dejar de acentuar que lo que caracteriza a lo femenino es únicamente lo irracional (como el apelativo de "La Maga" para el famoso personaje de Rayuela viene a confirmar). Es, por lo tanto, Puig, el que lleva a sus últimas consecuencias la discusión desde el momento en que en su primera novela (de 1968) La traición de Rita Hayworth, viene a debatir a caballo de cine y literatura los mitos del glamour que Hollywood, como fábrica de marcas de gender, había venido difundiendo a una escala que hacía que el problema se tornara internacional.

Si de todas las categorías mencionadas en este trabajo, ponemos nuestra atención en la FUERZA DEL MITO, veremos que el cuadrilátero de tensiones muestra una particular afinidad que hace que, en definitiva, estemos hablando de creadores de un mismo campo: el mito los amalgama. Con todo, si en alguno de los lados de la figura esto se siente particularmente vinculante, ello se da en la relación Borges-Cortázar. En este sentido, lo que Cortázar no le cuestiona al Maestro es haber ganado para la literatura argentina ese territorio. Pero esta afinidad se potencia, en tanto la FUERZA DE LO IDEOLÓGICO y la FUERZA DEL INCONSCIENTE van a ser las esferas discursivas más fuertemente postuladas desde el lado de la figura que ocupan, finalmente, Arlt y Puig, a quienes considero la punta de lanza para la renovación.

\section{Bibliografía}

Amícola, José. Astrología y fascismo en la obra de Arlt [1984]. Rosario: Beatriz Viterbo, 1994.

Manuel Puig y la tela que atrapa al lector. Buenos Aires: Grupo Editor de América Latina, 1992.

De la forma a la información. Bajtín y Lotman en el debate con el formalismo ruso. Rosario: Beatriz Viterbo, 1997.

“'La noche boca arriba' como encrucijada literaria”. Revista Iberoamericana LXIII/ 180 (julio-setiembre 1997): 459-466.

y Speranza (comps.). Encuentro Internacional Manuel Puig. Orbis Tertius 3. La Plata: Universidad Nacional de La Plata, 1998.

Arlt, Roberto. "Saverio el cruel”. [1936]. Obra completa II. Buenos Aires: Carlos Lohlé, 1981. 443-486.

Bloom, Harold. The Western Canon. Londres: Macmillan, 1995. 463-492.

Borré, Omar. Roberto Arlt y la crítica (1926-1990). Estudio, cronología y bibliografía. Buenos Aires: América Libre, 1996.

Bürger, Peter. Der französische Surrealismus. Francfort: Athenäum, 1971.

Cabrero, María del Carmen. "El mito del Minotauro y su proyección en Los Reyes de Cortázar”. AAVV, Tradición clásica y literaturas contemporáneas. Bahía Blanca: EDINUS (Editorial de la Universidad Nacional del Sur), 1996. 83-102.

Colas, Santiago. Postmodernity in Latin America. The Argentine Paradigma. Durham/ Londres: Duke University Press, 1994. 
Correas, Carlos. La operación Masotta (cuando la muerte también fracasa). Buenos Aires: Catálogos, 1991.

Cortázar, Julio. Los reyes. Buenos Aires: Croniamantal, 1949. y Ana María Barrenechea. Cuaderno de bitácora de Rayuela. Buenos Aires: Sudamericana, 1983.

Cosgrove, Ciaran. "Discursive Anarchy or Creative Pluralism? The Cases of Cortázar and Puig”. The Modern Language Review 90/1 (1995): 71-82.

Dalmaroni, Miguel. “Notas sobre 'populismo’y literatura argentina.(Algunos episodios en la historia de un debate, 1960-1994)”. Boletín del Centro de Estudios de Teoría y Crítica Literaria 5 (octubre, 1996). 91-110.

Foucault, Michel. Les mots et les choses. [1966]. París: Gallimard, 1983. 7.

Giordano, Alberto. "Manuel Puig: Micropolíticas literarias y conflictos culturales". Boletín del Centro de Estudios de Teoría y Crítica Literaria 5 (octubre, 1996). 17-34.

Harss, Luis. Los nuestros [1966]. Buenos Aires: Sudamericana, 1981.

Hunter, Priscilla. "Molina and the Weaving Goddesses: Thread Imagery in Manuel Puig's El beso de la mujer araña”. Critical Essays on the Literatures of Spain and Spanish America. L. T. González del Valle y J. Baena, comps. Boulder: Society of Spanish and Spanish American Studies, 1991. 133-144.

Jitrik, Noé. “1926, año decisivo para la narrativa argentina”. El escritor argentino. Dependencia o libertad [1965]. Buenos Aires: del Candil, 1967. 83-115.

Ludmer, Josefina. "Mujeres que matan”. Revista Iberoamericana LXII/176-177 (juliodiciembre 1996): 781-797.

Martí-Peña, Guadalupe. Manuel Puig ante la crítica. Bibliografía analítica y comentada (1968-1996). Francfort: Vervuert, 1997.

Masotta, Oscar. "Roberto Arlt - La plancha de metal”. Revista Centro 13 (Buenos Aires, 1959). 9-42.

"La fenomenología de Sartre y un trabajo de Daniel Lagache”. Revista Centro 13 (Buenos Aires, 1959). 71-83.

Sexo y traición en Roberto Arlt. Buenos Aires: J.Alvarez, 1965.

Ovidio. Les métamorphoses. París: Flammarion, s.a.

Puig, Manuel. Prólogo a La cara del villano/Recuerdo de Tijuana. Madrid: Seix Barral, 1985.

El misterio del ramo de rosas (junto con Bajo un manto de estrellas) [1987]. Rosario: Beatriz Viterbo Editora, 1997.

Rostagni, Augusto. Lineamenti di storia della letteratura greca. Milán: Mondadori, 1965.

Sarlo, Beatriz. "Los dos ojos de Contorno". Revista Iberoamericana XLIX/125 (octubrediciembre 1983): 797-807.

Borges, un escritor en las orillas [1993]. Buenos Aires: Ariel, 1995.

Steiner, George. No Passion Spent. Londres/Boston: Faber and Faber, 1997. 3-4.

Viñas, David. “El escritor vacilante: Arlt, Boedo y Discépolo”. Literatura argentina y realidad política. De Sarmiento a Cortázar [1964]. Buenos Aires: Siglo Veinte, 1974. 63-69.

Zubieta, Ana María. El discurso narrativo arltiano. Intertextualidad, grotesco y utopía. Buenos Aires: Hachette, 1987. 